\title{
Assessing the climate impact of district heating systems with combined heat and power production and industrial excess heat
}

\author{
Linda Olsson, Elisabeth Wetterlund and Mats Söderström
}

\section{Linköping University Post Print}

Tweet

N.B.: When citing this work, cite the original article.

Original Publication:

Linda Olsson, Elisabeth Wetterlund and Mats Söderström, Assessing the climate impact of district heating systems with combined heat and power production and industrial excess heat, 2015, Resources, Conservation and Recycling, (86), 31-39.

http://dx.doi.org/10.1016/j.resconrec.2015.01.006

Copyright: Elsevier

http://www.elsevier.com/

Postprint available at: Linköping University Electronic Press

http://urn.kb.se/resolve?urn=urn:nbn:se:liu:diva-114402 


\title{
Assessing the climate impact of district heating systems with combined heat and power production and industrial excess heat
}

Linda Olsson ${ }^{\mathrm{a}, *}$, Elisabeth Wetterlund ${ }^{\mathrm{b}}$, Mats Söderström ${ }^{\mathrm{a}}$

${ }^{a}$ Department of Management and Engineering, Division of Energy Systems, Linköping University, SE-581 83 Linköping, Sweden.

E-mail: linda.olsson@liu.se, mats.soderstrom@liu.se.

${ }^{\mathrm{b}}$ Department of Engineering Sciences and Mathematics, Division of Energy Science, Luleå University of Technology, SE-971 87 Luleå, Sweden.

E-mail: elisabeth.wetterlund@ltu.se.

*Corresponding author:

Linda Olsson

Department of Management and Engineering, Division of Energy Systems, Linköping University, SE-58183 Linköping, Sweden

Tel.: +4613285664

\begin{abstract}
Heat demand is a large contributor to greenhouse gas (GHG) emissions in the European Union (EU), as heat is largely produced using fossil fuel resources. Extended use of district heating (DH) could reduce climate impact, as DH systems can distribute heat produced in efficient combined heat and power (CHP) plants and industrial excess heat, thus utilising heat that would otherwise be wasted. The difficulty to estimate and compare GHG emissions from DH systems can however constitute an obstacle to an expanded implementation of DH. There are several methods for GHG emission assessments that may be used with varying assumptions and system boundaries. The aim of this paper is to illuminate how methodological choices affect the results of studies estimating GHG emissions from DH systems, and to suggest how awareness of this can be used to identify possibilities for GHG emission reductions. DH systems with CHP production and industrial excess heat are analysed and discussed in a systems approach. We apply different methods for allocating GHG emissions between products and combine them with different system boundaries. In addition, we discuss the impact of resource efficiency on GHG emissions, using the framework of industrial symbiosis (IS). We conclude that assessments of the climate impact of DH systems should take local conditions and requirements into account. In order for heat from CHP production and industrial excess heat to be comparable, heat should be considered a by-product regardless of its origin. That could also reveal opportunities for GHG emission reductions.
\end{abstract}

Keywords: Systems analysis, District heating, Greenhouse gas emissions, Resource efficiency, Combined heat and power, Industrial excess heat 


\section{Introduction}

Heating makes up a large share of the energy use within the European Union (EU). With the main technologies for heat production being individual gas or oil boilers (Connolly et al., 2014), greenhouse gas (GHG) emissions from heating are high. In order to reduce GHG emissions from heating, EU policy encourages district heating (DH) (EC, 2009, 2012). Europe has a large unutilised heat potential, mainly accessible by implementation of combined heat and power (CHP) plants and utilisation of industrial excess heat (Connolly et al., 2014; Persson and Werner, 2012). This heat could be distributed in DH grids, thereby reducing the need for individual boilers. DH could also be used to produce cooling, and CHP plants would add efficiently (and possibly renewably) produced electricity to the European energy system. Currently, DH is primarily implemented in the Nordic and Baltic countries, but it is estimated that more than 1000 TWh of new DH could be implemented in populationdense areas throughout the EU until 2050 (Connolly et al., 2014). The ongoing urbanisation entails challenges for citizens and the environment, but it also offers opportunities for increased well-being (EC, 2014; Nijkamp and Kourtit, 2013). DH could make an important contribution to efficient and cost-effective use of energy and resources in urban areas (EC, 2012; Persson and Werner, 2011). Positive effects include improved urban air quality, as DH drastically reduces particulate matter compared to individual boiler installations (Caserini et al., 2010).

The difficulty to estimate GHG emissions and to compare the climate impact of DH to that of other heating options may constitute an obstacle to expanded implementation of DH. There are several methods to calculate GHG emissions, in which different system boundaries and assumptions about the system under study can be applied. Depending on which method that is used, the results and the possibility to compare the results to other heating options may differ. In a DH system with CHP production, estimating climate impact is a complex task because of the issue of allocation of GHG emissions between the two products, electricity and heat. Adding industrial excess heat to the DH system adds another dimension to the estimation of climate impact: what are the GHG emissions from a by-product of an industrial production process? This question introduces resource efficiency as an additional variable in the climate impact assessments, thus further increasing the complexity of the analysis.

The results from energy system analyses estimating GHG emissions have an impact on policy decisions, and thus also the future development of European energy systems. Therefore, it is crucial that such analyses provide reliable and comparable results, and that there is transparency in the use of methods and assumptions. In this paper, the consequences of using different allocation principles and system boundaries when estimating GHG emissions from CHP production and industrial excess heat are analysed. The aim is to illuminate the influence of methodological choices on the results and to suggest how awareness of this can be used to identify GHG emission reduction possibilities in DH systems with CHP production and/or industrial excess heat.

The climate impact of DH is a well-researched area (see for example Connolly et al., 2014; Lund et al., 2014; Magnusson, 2012; Persson and Werner, 2012; and Rezaie and Rosen, 
2012). There are also several previous studies of the consequences of applying different system boundaries (see for example Borrion et al.,2012; Grönkvist et al., 2003 and Wetterlund et al., 2010) and GHG emission allocation methods (see for example Beretta et al., 2012, Jungmeier et al., 1998 and Rosen, 2008), with regard to heat as well as other energy carriers. In this paper we complement previous research by applying different methodologies to a DH system with CHP production and industrial excess heat, thus illuminating the difficulties that appear when assessing the two great potential heat sources in the EU. We do this by bringing together GHG emissions calculation methods with the concept of industrial symbiosis (IS), which addresses resource efficiency in collaborations between industries and/or energy utilities. Results from this type of holistic approach to the assessment of GHG emissions from DH systems could be useful in the design of policies intended to encourage further development of $\mathrm{DH}$ in the EU.

The structure of this paper is as follows: In section 2, we provide a background with regard to DH, CHP production, and industrial excess heat. Section 3 presents the systems approach used to analyse GHG emissions and resource efficiency in this paper. Section 4 illustrates the complexity of estimating GHG emissions and resource efficiency of DH systems. In section 5 we discuss the consequences of using different methodologies for the implementation of DH systems. Section 6 concludes the paper and offers suggestions for further research.

\section{An overview of district heating}

\subsection{Using district heating}

Current DH systems primarily supply space heating and hot tap water to multi-family dwellings and non-residential buildings. Research shows that DH may contribute to reducing energy use in industries, by replacing other energy use in production processes (Difs et al., 2009; Henning and Trygg, 2008). Using DH for cooling purposes may also have large potential, through absorption cooling (Difs et al., 2009; Svensson and Moshfegh, 2011). This diversity of applications ensures that DH may be useful not only in countries with a cold climate but also in regions where space heating is not extensively required. Buildings and industrial production processes are becoming more energy efficient, thereby reducing the need for heating (Magnusson, 2012). For instance, buildings may be made energy efficient by improving insulation and ventilation or modifying the heating system. However, studies show that energy efficiency measures in buildings with DH are beneficial from a GHG emissions perspective, as they reduce peak load and level out the annual demand for DH (Åberg and Henning, 2011; Åberg et al., 2012). Thus, DH may continue to be useful. It has also been shown that DH offers flexibility to national energy systems, not only with regard to heat utilisation but also for energy storage capacity (Münster et al., 2012). In that respect DH could contribute to a renewable electricity system, as for instance a large share of wind power requires system functions that can manage fluctuations in electricity supply. 


\subsection{Heat supply}

\subsubsection{Combined heat and power production}

In a CHP plant, heat and electricity are produced simultaneously. The EU acknowledges the important role of CHP production in the energy efficiency directive (EED), in which the efficiency of cogeneration as opposed to separate production of electricity and heat is emphasised (EC, 2012). In particular, the efficiency of electricity production is targeted, as the total efficiency of a CHP plant is around $85 \%$ whereas the efficiency of a condensing power plant is $30-50 \%$ (Odenberger et al., 2009). Waste, biomass, and natural gas (NG) are commonly used fuels in CHP plants. Using waste in CHP production is one option to reduce landfilling, which is common in several EU member states (Persson and Werner, 2012). Studies also show that CHP plants may effectively reduce GHG emissions in the energy system (Henning and Trygg, 2008; Knutsson et al., 2006). In a renewable energy system, CHP plants are considered important for regulation and stabilisation of the electricity grid (Lund et al., 2014).

\subsubsection{Industrial excess heat}

A significant amount of heat is generated as a by-product from industrial production processes (see for example Broberg Viklund and Johansson, 2014). The heat flows have different characteristics, for example regarding quality (temperature) and form (such as exhaust gases, cooling water, or materials). In some cases the heat may be recovered and used in other processes within the industry, but if that is not possible it is considered excess heat. There are different definitions of exactly what constitutes excess heat, but in this paper we use the following definition: "Excess energy that cannot be utilised internally and where the alternative is that the heat is released into the surroundings" (SEA, 2008: p. 23).

Although the use of industrial excess heat, for example in DH systems, is endorsed in the EED (EC, 2012), it is currently not widely established. In Sweden, the EU member state where industrial excess heat is most widely used, 4.9 TWh was used in 2008 (Persson and Werner, 2012). Meanwhile, the total EU potential has been estimated at $750 \mathrm{TWh}$ per year, of which less than $1 \%$ is currently used in DH systems (Connolly et al., 2014). Several barriers to excess heat collaborations have been identified, mainly related to social, cultural, and economic factors (Grönkvist and Sandberg, 2006; Thollander et al., 2010). The technical opportunities for using industrial excess heat in DH systems exist, and studies demonstrate a great deal of potential for this. For example, Johansson and Söderström (2011) found that the Swedish steel industry could become more energy efficient by supplying excess heat to DH systems; Johansson et al. (2012) identified excess heat supply to a DH grid as an option for the oil refining industry to reduce GHG emissions; and Jönsson and Algehed (2010) found that a DH collaboration would be an economically robust alternative for the pulp and paper industry to reduce GHG emissions. 


\section{A systems approach to assessing climate impact}

In this paper, we use a systems approach to identify and analyse problems associated with assessing GHG emissions and resource efficiency in DH systems. We use a mix of theories and methods in order to illuminate complexities. To address GHG emission assessments, we present and discuss different calculation methods. To address resource efficiency assessments, we apply ideas from the research field of IS. In this section, we describe the present application of these theories and methods.

The systems approach implies a holistic view rather than a focus on specific parts. A system is commonly defined as consisting of components and connections between them. It is separated from its environment by a system boundary. Although systems are often considered in technological terms, social and economic aspects may also be included (Ingelstam, 2012). Here, the system's components are DH production, distribution and use, resources used, and GHG emissions, as illustrated in Figure 1. Avoided resource use and alternative production are also of interest. Depending on system perspective, the latter may be part of the system or the environment. The implications of moving the system boundary will be addressed throughout this section.

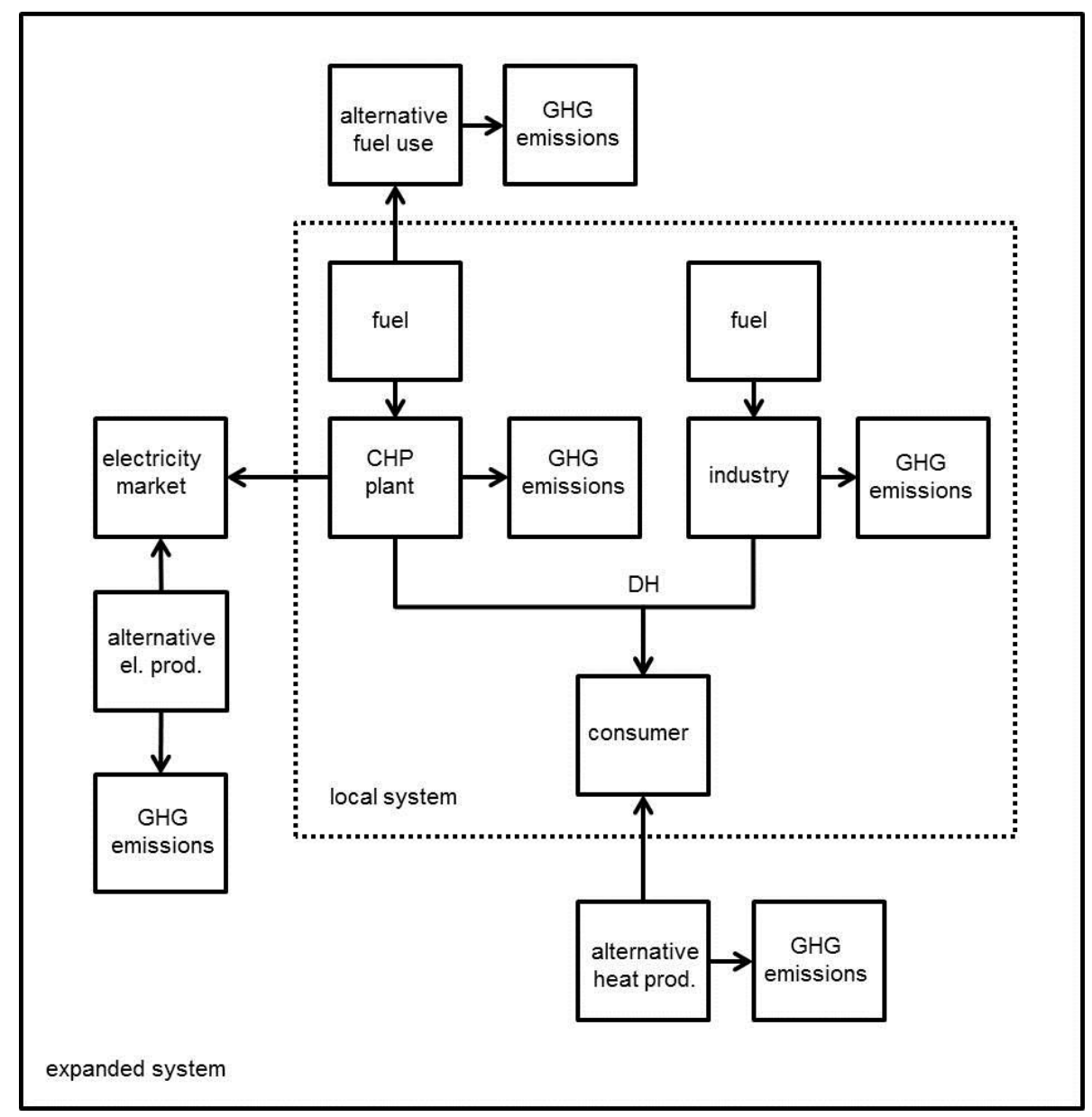

Figure 1. The system under study. The dashed line represents the boundary of the local system, which consists of production and use of DH. The solid line represents the boundary of the expanded system, which also includes alternative production of heat and electricity and alternative fuel use. 


\subsection{GHG emissions calculations in different system perspectives}

Several system mechanisms are associated with GHG emissions, as Figure 1 shows. Analyses of how different actions affect GHG emissions are influenced by the choice of system boundary and by assumptions about the components and environment of the system (cf. Borrion et al., 2012; Grönkvist et al., 2003; Wetterlund et al., 2010). In this paper, the local system is that of the DH system, including heat production in CHP plants and industries, use of DH, and related GHG emissions. Although calculations become more complex, expanding the system boundaries to also include alternatives to production processes and fuel use, and related GHG emissions, could provide more accurate estimations of the GHG emissions associated with DH systems.

Different methodologies are appropriate when analysing existing systems or consequences of changes to systems. Some researchers recommend that when analysing an existing system, an attributional (book-keeping, retrospective) approach may be used, while a consequential (marginal, prospective) approach is preferable when analysing a potential change to the system (see for example Dotzauer, 2010 and Ekvall et al., 2005). Others argue that in a comprehensive analysis, both approaches should be employed (Burström von Malmborg and Forsberg, 2003).

In the attributional approach all input data, such as GHG emissions from electricity and heat production, are known (as they have already occurred). With respect to electricity, the average electricity production mix is often used in calculations (Dotzauer, 2010; Ekvall et al., 2005). The use of average mix, for example national or regional, depends on where the system boundary is drawn. With respect to heat, local conditions largely determine what values should be used in calculations. As heat is a local product, the average heat production mix is individual in every community.

In the consequential approach, changes to energy conversion and use are assumed to affect the system on the margin. The last used or produced unit of heat or electricity is the marginal unit, and this marginal unit is affected by changes. For instance, an increase in electricity use requires an increase in electricity production, which occurs on the margin. The consequential approach is used slightly differently depending on time frame (Dotzauer, 2010). In a shortterm perspective, based on the current energy system, the so-called operating margin is used. In a longer perspective, where the energy system is not known, the so-called build margin is used. When using the build margin, assumptions about future energy conversion technology decide what kind of marginal unit is used in calculations. For a thorough background to the marginal displacement of electricity, see for example Carlson (2003), Sjödin and Grönkvist (2004), and WRI (2007).

In the consequential approach we use in this paper, we assume DH to replace other heat, and electricity from CHP plants to replace other electricity. We calculate the GHG emissions as those of the DH production minus those of the replaced production. Thus, the GHG emissions of several heat and electricity production options, not only for the $\mathrm{DH}$ production, need to be included in the analysis. With respect to electricity, both operating and build margins are 
often assumed to be fossil fuel-based (coal or NG) production (see for example Djuric Ilic et al., 2014). With respect to heat, new DH (based on CHP or industrial excess heat) might currently replace older, fossil fuel-based household boilers or heat plants. In a longer perspective, the build margin for heat production might contain biomass-based heat plants and household heat pumps (see for example Magnusson, 2012 and Münster et al., 2012).

\subsection{Allocation of GHG emissions between products}

Allocation is of interest when a production process results in two or more products, and the GHG emissions from each product are to be estimated. This applies both to CHP production and to industrial production processes that result in excess heat. However, allocating environmental impact to industrial excess heat is complicated. Although allocation may be useful for comparing excess heat with heat of other origins, it may also be argued that allocation is unnecessary; assuming that the use of otherwise wasted energy is always environmentally beneficial (SEA, 2008). In this paper, we make the latter assumption. Therefore, this section only deals with allocation of GHG emissions from CHP production.

Depending on which kind of production is concerned, different allocation principles may be used, for example based on mass, economic value, or energy content. With regard to CHP production, principles based on energy content are suitable. There are however several principles within this segment, for which the consequences of application on CHP production have been studied previously. Jungmeier et al. (1998) show the differing results from applying seven allocation methods to biomass-based CHP production. They conclude that the wide variety of allocation methods makes comparison with other fuels extremely difficult. Rosen (2008) presents six allocation methods in detail and then argues that a common methodology would benefit cogeneration, as it would simplify evaluation of environmental impact. Beretta et al. (2012) present four common allocation methods and argue that a new method is required, as the common ones do not take local conditions into account. They point out that DH systems may contain a wide variety of energy sources and users, and this should be acknowledged when energy use and environmental impact are estimated.

In this paper, we exemplify five principles for allocation of GHG emissions between electricity and heat produced in CHP plants. The principles are explained in this section and described by Tables 1 and 2. Allocation to electricity and allocation to heat are the most straightforward principles. If heat is considered a by-product of electricity production, all GHG emissions may be allocated to the produced electricity. Similarly, if heat is considered the main product, all GHG emissions may be allocated to the heat. Energy allocation, that is, allocating GHG emissions based on the energy content, is advocated due to its simplicity (EC, 2009). In that method, the different characteristics of heat and electricity are not accounted for. According to Rosen (2008), allocation should instead be based on exergy content; in other words, the energy quality should be taken into account. The exergy allocation principle reflects that electricity is more useful than heat. In the EED, the calculation of the energy efficiency of CHP production takes the efficiency of separate production of heat and electricity into account (EC, 2012). This is also done in efficiency allocation, sometimes also called the benefit-sharing method. If heat and electricity were 
produced in separate plants, more fuel would be required. Hence, electricity and heat produced in a CHP plant share the savings made by the combined production. The allocation of savings depends on the efficiency of the separate production and the CHP production.

Table 1. Principles for allocation of environmental impact used in this paper.

\begin{tabular}{lll}
\hline Allocation principle & Allocation factor, electricity & Allocation factor, heat \\
\hline Allocation to electricity & $100 \%$ & $0 \%$ \\
\hline Allocation to heat & $0 \%$ & $100 \%$ \\
\hline Energy allocation & $A_{E}=\frac{Q_{E}}{Q_{E}+Q_{H}}$ & $A_{H}=\frac{Q_{H}}{Q_{E}+Q_{H}}$ \\
\hline Exergy allocation & $A_{E}=\frac{E x_{E} * Q_{E}}{E x_{E} * Q_{E}+E x_{H} * Q_{H}}$ & $A_{H}=\frac{E x_{H} * Q_{H}}{E x_{E} * Q_{E}+E x_{H} * Q_{H}}$ \\
\hline Efficiency allocation & $A_{E}=\frac{\frac{Q_{E}}{\eta_{E}}}{\frac{Q_{E}}{\eta_{E}+\frac{Q_{H}}{\eta_{H}}}}$ & $A_{H}=\frac{\frac{Q_{H}}{\eta_{H}}}{\frac{Q_{E}}{\eta_{E}}+\frac{Q_{H}}{\eta_{H}}}$ \\
\hline
\end{tabular}

Table 2. Variables used in Table 1.

\begin{tabular}{ll}
\hline$A_{\mathrm{E}}$ & Allocation factor for electricity \\
\hline $\mathrm{A}_{\mathrm{H}}$ & Allocation factor for heat \\
\hline $\mathrm{Q}_{\mathrm{E}}$ & Net electricity production in CHP plant \\
\hline $\mathrm{Q}_{\mathrm{H}}$ & Net heat production in CHP plant \\
\hline$\eta_{\mathrm{E}}$ & Assumed efficiency in separate electricity production \\
\hline$\eta_{\mathrm{H}}$ & Assumed efficiency in separate heat production \\
\hline $\mathrm{Ex}_{\mathrm{E}}$ & Exergy factor for electricity \\
\hline $\mathrm{Ex}_{\mathrm{H}}$ & Exergy factor for heat \\
\hline
\end{tabular}

\subsection{Resource efficiency}

As mentioned in section 1, resource efficiency is an important aspect to consider with regard to the climate impact of a system. Here, we use an IS framework to address resource efficiency in the local system as well as in the expanded system. IS is an approach to increase resource efficiency in industrial production, by resource exchange between different actors. The most cited definition of IS originates from Chertow (2000: p. 313): "Industrial symbiosis engages traditionally separate industries in a collective approach to competitive advantage involving physical exchange of materials, energy, water, and/or by-products. The keys to industrial symbiosis are collaboration and the synergistic possibilities offered by geographic proximity." As DH systems are in essence exchanges of hot water between geographically close actors, IS is well suited to analysing DH systems.

We use the IS framework to identify and discuss potential DH collaborations between industries and communities. Industries may be part of DH systems either by supplying excess heat, or by receiving heat for use in their production processes and facilities. A CHP plant may also be an actor in an IS network. In several IS networks, the so-called anchor tenant is a CHP plant (Martin and Eklund, 2011). An anchor tenant has the possibility to connect to several other industries by offering a range of inputs and outputs, thus acting as the anchor for a collaboration (Wolf et al., 2005). A CHP plant may use other actors' waste, such as 
municipal waste or wood chips, as fuel and may produce heat, steam, and electricity to be used by other actors.

In this paper, a qualitative approach to IS is used. Our approach is inspired by a study by Martin and Eklund (2011), in which they show how biofuel industries may benefit from IS, applying a generic framework. In their framework, material and energy flows are mapped, possible synergies are identified, and IS theories are applied. This approach is equally applicable to assessments of potential heat collaborations. Possible heat flows between industries, CHP plants, and communities can be mapped, and synergies between actors with regard to heat demand and available excess heat identified. The feasibility of heat collaborations should be taken into account, as all collaborations might not be realised due to social or economic factors. Based on this, resource efficiency can be assessed. Local conditions and requirements should affect assessments. Different regions have different priorities, affecting which system and what qualities are considered best (Wolf et al., 2007).

The environmental impact of an implementation of IS can be quantified, using for example life cycle assessment (LCA) (see for example Martin et al., 2014 and Sokka et al., 2011). However, the usefulness of such quantifications may be questioned. The choice of input data and system boundaries affects results, as is the case in all quantifications. In the case of IS the human dimension also affects the system and the choices of input data. There are several reasons why IS may be implemented, many of which may not seem rational from a purely environmental or economic point of view (Brings Jacobsen, 2007; Martin, 2013). If it is not clear why IS is implemented or improved, or what the alternatives are, quantifications are difficult to make.

\section{Illustrating the complexity of assessing GHG emissions in DH systems}

\subsection{GHG emission calculations}

In sections 3.1 and 3.2, we presented principles for estimating GHG emissions. In this section, we apply these principles on a non-specific DH system case to which CHP production and industrial excess heat are added. We assume the case to be located in Sweden, as effects of system expansion are well-illustrated by a case in which national data differ from European data. With regard to electricity production, Sweden has low GHG emissions ( $79 \mathrm{~g} \mathrm{CO}_{2} \mathrm{eq} / \mathrm{kWh}$ on average) while the European average is fairly high (578 $\mathrm{g} \mathrm{CO}_{2}$ eq/kWh) (Covenant of Mayors, 2012). Introducing CHP thus has different effects depending on the system boundaries in the analysis, which is something that this example is intended to visualise. The example is based on NG-fuelled CHP production, as NG is extensively used in recent and planned European power plants (CPPD, 2014). We use an existing CHP plant, built in 2006 in Gothenburg and used in previous studies (GE, 2014; Holmgren, 2006), in order to present realistic data.

An overview of which technologies that are associated with attributional and consequential approaches in our example is presented in Table 3. With regard to electricity, an attributional approach may be assumed; using GHG emissions from an average electricity mix. However, for the most part, we assume a consequential approach. Coal and NG are assumed to be used 
in marginal production. As carbon capture and storage (CCS) could be an important future technology, this option is included with coal condensing power production. With regard to heat, we assume oil-based heat production to constitute operating margin technologies, and biomass-based heat production and heat pumps to constitute build margin technologies. We disregard an attributional approach to heat production as a local heat mix cannot be generalised.

Table 3. Schematic of which technologies that are associated with different approaches to GHG emissions accounting for electricity and heat production.

\begin{tabular}{c|l|l|l|l|l}
\multicolumn{2}{c|}{ Electricity } & \multicolumn{2}{c}{ Heat } \\
\hline Attributional & \multicolumn{2}{|c}{ Consequential } & Attributional & \multicolumn{2}{c}{ Consequential } \\
\hline $\begin{array}{l}\text { Swedish and } \\
\text { European mix }\end{array}$ & $\begin{array}{l}\text { Production on } \\
\text { operating margin }\end{array}$ & $\begin{array}{l}\text { Production on } \\
\text { build margin }\end{array}$ & Local mix) & $\begin{array}{l}\text { Production on } \\
\text { operating margin }\end{array}$ & $\begin{array}{l}\text { Production on } \\
\text { build margin }\end{array}$ \\
\cline { 2 - 3 } \cline { 5 - 6 } & Coal condensing & $\begin{array}{l}\text { Coal condensing } \\
\text { Natural gas } \\
\text { combined cycle }\end{array}$ & & $\begin{array}{l}\text { Oil-fired heat plants } \\
\text { and household } \\
\text { boilers }\end{array}$ & $\begin{array}{l}\text { Heat pumps } \\
\text { Biomass-fired } \\
\text { heat plants and } \\
\text { household boilers }\end{array}$
\end{tabular}

Data that are used in the example are presented in Tables 4 to 6 . In Table 4, we provide three examples of electricity production build margin (time frame: 2020-2030) and one of operating margin. In Table 5, we provide data for heat production based on oil, biomass, NG and electricity. For electric heat pumps, we assume coefficient of performance (COP) to be 3.0 (Joelsson and Gustavsson, 2010). When applying one of the allocation principles, we assume NG-based heat production. In Table 6, we present data for the NG CHP plant, along with data for comparable separate NG-fuelled electricity and heat. The latter are included as we use that data in one of the allocation methods.

Table 4. GHG emissions from electricity production, applying attributional and consequential perspectives. All emissions are calculated using a life cycle perspective. (CC - coal condensing; CCS carbon capture and storage; NGCC - natural gas combined cycle)

\begin{tabular}{|c|c|}
\hline Electricity production & GHG emissions [g CO $2 \mathrm{eq} / \mathrm{kWh}$ ] \\
\hline Swedish average mix $^{\mathrm{a}}$ & 79 \\
\hline European average mix $^{\mathrm{a}}$ & 578 \\
\hline CC power plant, operating margin ${ }^{\mathrm{b}}$ & 1039 \\
\hline CC power plant, build margin ${ }^{\mathrm{b}}$ & 786 \\
\hline CC power plant with CCS, build margin ${ }^{\mathrm{b}}$ & 207 \\
\hline NGCC power plant, build margin $^{c}$ & 345 \\
\hline${ }^{\mathrm{a}}$ Covenant of Mayors (2012). & \\
\hline
\end{tabular}


Table 5. GHG emissions from heat production. All emissions are calculated using a life cycle perspective. The biomass is assumed to be wood. Source: Uppenberg et al. (2001).

\begin{tabular}{llc}
\hline Fuel & Production & GHG emissions [g CO $\mathbf{~ e q} / \mathbf{k W h}$ ] \\
\hline Biomass & Household boiler & 30 \\
\hline Biomass & Heat plant (DH) & 16 \\
\hline Oil & Household boiler & 343 \\
\hline Oil & Heat plant (DH) & 325 \\
\hline Natural gas & Heat plant (DH) & 210 \\
\hline Electricity & Heat pump & $\begin{array}{l}\text { Depends on assumed } \\
\text { electricity production }\end{array}$ \\
\hline
\end{tabular}

Table 6. Data for the NG CHP plant and for separate NG-based heat and electricity production.

\begin{tabular}{|c|c|}
\hline Variable & Value \\
\hline GHG emissions $^{\mathrm{a}}$ & $241 \mathrm{~g} \mathrm{CO}_{2} \mathrm{eq} / \mathrm{kWh}$ \\
\hline $\mathrm{QE}^{\mathrm{b}}$ & $261 \mathrm{MW}$ \\
\hline $\mathrm{QH}^{\mathrm{b}}$ & $294 \mathrm{MW}$ \\
\hline$\eta_{\mathrm{CHP}}{ }^{\mathrm{b}}$ & 0.925 \\
\hline$\eta_{E}^{c}$ & 0.53 \\
\hline$\eta_{H^{c}}$ & 0.90 \\
\hline $\operatorname{Ex}_{\mathrm{E}}^{\mathrm{d}}$ & 1 \\
\hline $\mathrm{Ex}_{\mathrm{H}}^{\mathrm{d}}$ & 0.215 \\
\hline \multicolumn{2}{|c|}{ a Gode et al. (2011), GE (2014) } \\
\hline \multicolumn{2}{|c|}{${ }^{\mathrm{b}} \mathrm{GE}(2014)$} \\
\hline \multicolumn{2}{|l|}{${ }^{\mathrm{c}} \mathrm{EC}(2011)$} \\
\hline
\end{tabular}

\subsubsection{GHG emissions from CHP production in a DH system}

The most local system perspective of CHP production in a DH system is that of the CHP plant itself. In this case, the GHG emissions are known from literature but their allocation between produced electricity and heat may be estimated, using the principles described in section 3.2. This estimation is illustrated in Figure 2.

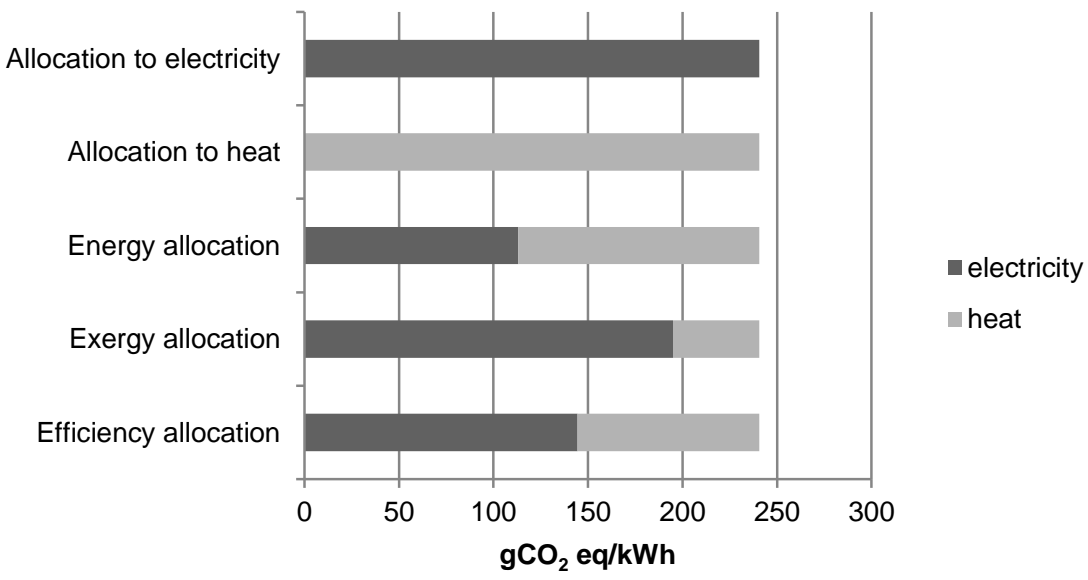

Figure 2. Local GHG emissions per kWh energy output from the NG-fuelled CHP plant according to different allocation principles. 
By expanding the system, the GHG emissions are estimated differently. In Figure 3, we apply the same allocation principles as in Figure 2, but here in combination with expanded system boundaries. We assume other electricity and heat production to be replaced by the production in the new NG-fuelled CHP plant. For allocation to electricity, we assume only electricity to be replaced. Similarly, for allocation to heat, we assume only heat replacement. For energy, exergy, and efficiency allocation, we assume both heat and electricity to be replaced. We base the illustration in Figure 3 on the overview in Table 3, but for the sake of visualisation we also choose to use some extremes (electricity or heat production with very high or very low GHG emissions) in order to show the range of possible results.

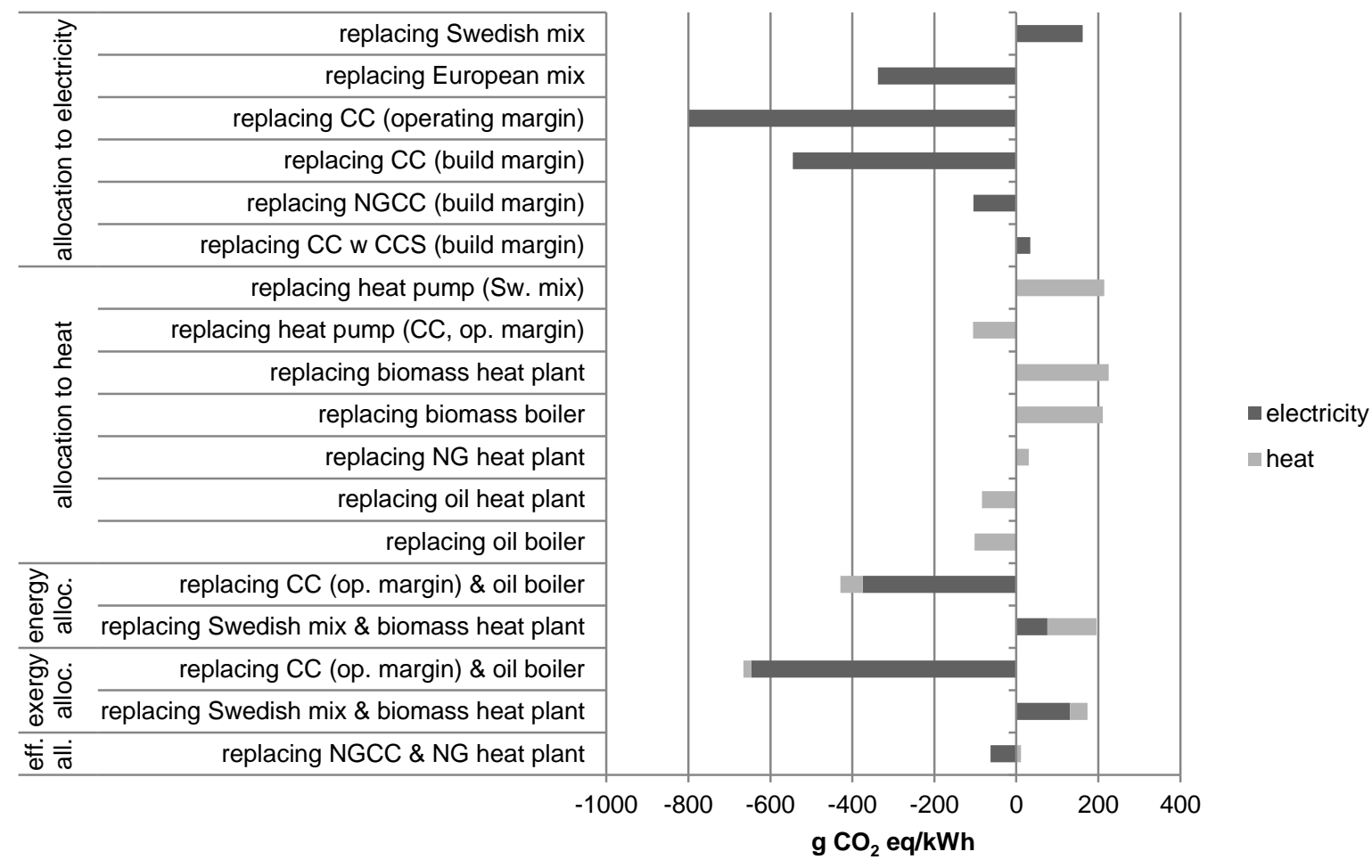

Figure 3. GHG emissions from the implementation of an NG-fuelled CHP plant, applying different allocation principles and system perspectives. With energy and exergy allocation, the visualised system perspectives are two extremes. With efficiency allocation, which compares CHP production to separate electricity and heat production using the same fuel, NG is used in replacement technologies.

It is obvious from Figure 3 that methodology, system boundaries, and assumptions affect the result of a systems analysis of GHG emissions from a DH system with CHP production. Just as none of the bars in Figure 3 are wrong, it is likely that none of them provide enough information on their own. When assessing this kind of system, a variation of system boundaries may be necessary in order to demonstrate the range of possible system effects.

\subsubsection{GHG emissions from industrial excess heat in a DH system}

When including industrial excess heat in the DH system, matters are complicated further. This situation is illustrated in Figure 4, where the system is expanded to show the effects on heat and electricity production, respectively. In the case of expansion with respect to heat, 
this is straightforward, as another heat-producing technology is replaced. In the case of expansion with respect to electricity, we assume that the alternative to industrial excess heat would be heat from the NG-fuelled CHP plant used in the previous example. With the inclusion of industrial excess heat in the DH system, we assume the NG plant not to be built, which consequently means that no electricity production can be replaced (as would have been the case with new CHP production). In this example, we assume that industrial excess heat carries zero GHG emissions.

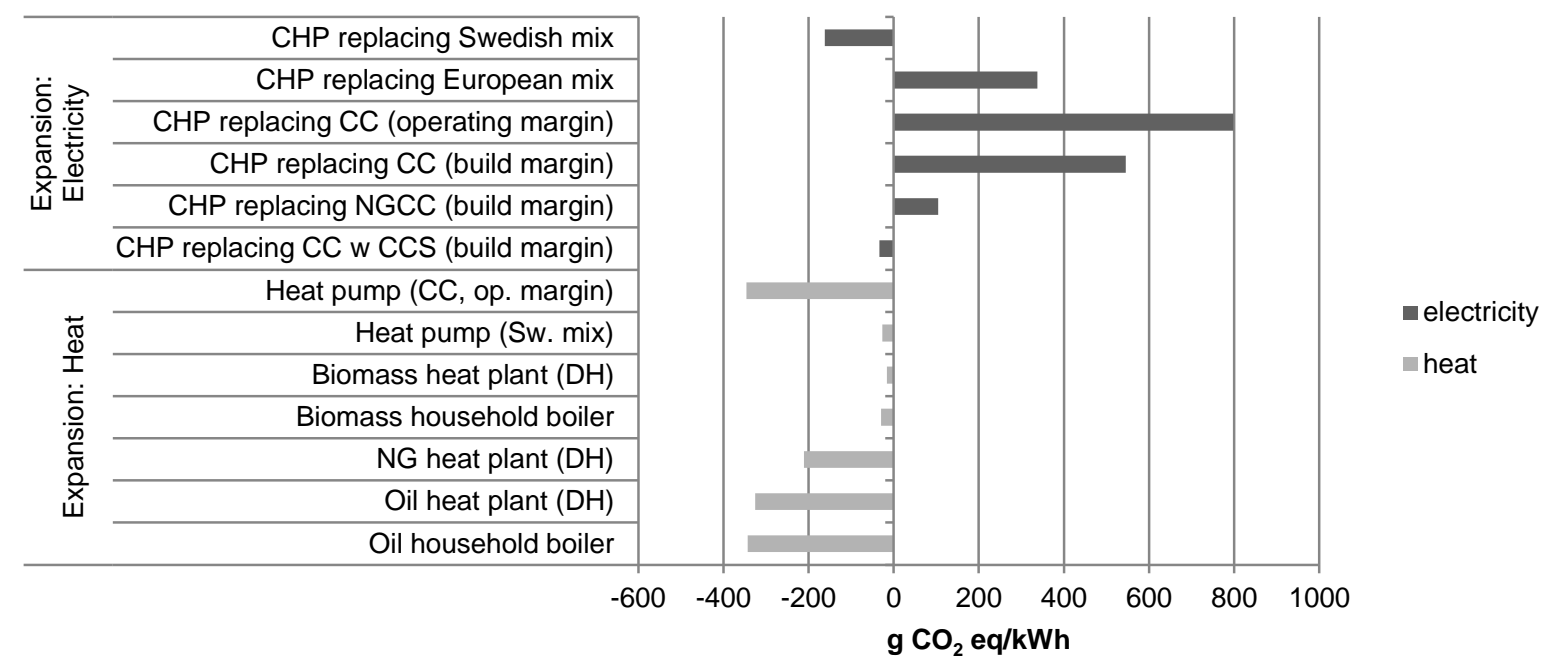

Figure 4. Two examples of system expansion concerning industrial excess heat: one in which the excess heat substitutes CHP production (thus counteracting electricity production), and one in which the excess heat replaces other heat.

Again, the effect of varying system boundaries is evident. When expanding the system to contain other heat-only production, the use of industrial excess heat appears beneficial from a GHG emissions point of view. To instead expand the system to contain CHP production could be argued to be a more relevant comparison, since industrial excess heat and CHP heat in general both constitute base load or close to base load. In this case the system would need to also be expanded to include electricity production. With the assumption that CHP production would not be required due to the use of industrial excess heat, the loss of electricity production that would have occurred in a CHP plant may be shown to actually increase GHG emissions.

\subsection{Assessing resource efficiency}

Section 4.1 showed how methodological choices affect results of energy systems analyses. The system perspective may also affect results, by defining which actors that are regarded as part of a DH system.

Using industrial excess heat in a DH system would be resource efficient, unless the industry could reduce the amount of excess heat. As industries may refrain from optimising their processes to be able to sell excess heat, the use of industrial excess heat may result in greater resource use (Svensson, 2011). To visualise this eventuality, part of the GHG emissions of 
the production process could be allocated to the excess heat. This allocation could however be counterproductive, as it could shift focus from the industry's process efficiency to other measures. An analogous example: In Sweden, where industrial excess heat is the most used in Europe (Persson and Werner, 2012), industrial excess heat may be eco-labelled if the production process is based on renewable energy (SSNC, 2013). Otherwise, industrial excess heat may not be eco-labelled. This practice differentiates between the "good" excess heat and the "dirty" excess heat, in a sense allocating GHG emissions to one but not to the other. As the same criteria apply to dedicated heat production, heat from a biomass-fuelled boiler may be eco-labelled. Thus, it may seem environmentally beneficial to install a new biomass-fired boiler rather than utilising excess heat from a fossil fuel-based industrial process, even though more resources are used. This is a reason why it may be preferable not to allocate GHG emissions to industrial excess heat regardless of its origin.

As an anchor tenant, a CHP plant could create possibilities for new collaborations between industries. A waste- or biomass-fuelled CHP plant could use output from nearby industries and municipalities as well as provide heat and electricity to them (see for example Holmgren and Gebremedhin, 2004 and Martin and Eklund, 2011). One example of successful use of both industrial excess heat and CHP plants in a large DH system is that of Gothenburg in Sweden. Holmgren (2006) found that aside from the environmental benefits from using excess heat, there was no competition between a new NG-fired CHP plant and the use of industrial excess heat from a nearby oil refinery in Gothenburg's DH grid. Decreasing the use of excess heat would increase the system's costs as well as GHG emissions (Holmgren, 2006). Close proximity between an oil refinery and a large DH grid may thus benefit the industry, the DH system operator, and the DH consumers. As it is unlikely that this oil refinery will shut down in the foreseeable future, it should also be considered resource efficient to utilise their excess heat.

Martin et al. (2013) developed a method for calculating the sharing of benefits from increased resource efficiency within an IS network, that could encourage collaborations as involved actors would easily identify their benefits. Such a method would illuminate the benefits of IS. However, there is also concern that resource exchanges could dissuade involved actors from implementing efficiency measures in their production processes, as wasting energy and resources almost becomes a virtue in the symbiosis (O'Rourke et al., 1996). It may be more profitable to sell a waste product to another actor rather than implement measures to reduce the creation of waste products, and it may also seem more environmentally beneficial to exchange resources than to increase individual resource efficiency. Therefore, heat collaborations should not automatically be considered resource efficient.

\section{Discussion}

The assessment of GHG emissions from a non-specific DH system presented in section 4.1 demonstrates clearly to what extent the choice of methodology, assumptions, and system boundaries affects results. This has been demonstrated also in other studies and is worth emphasising again as it is important to understand the consequences of methodological choices. The discussion in section 4.2 illustrates the complexity of assessing resource 
efficiency in a system that not only consists of technology but also contains highly influential social and economic factors. Although it might not be possible to identify one single correct methodology for assessments of this kind, the complexity and the possible diversity of results may serve as advocates for the need for a common methodology.

A common methodology could benefit assessments of GHG emissions and resource efficiency in DH systems by giving them greater reliability. If all systems were evaluated according to the same principles, they would be comparable and results could be useful in other cases than the analysed ones. Yet a common methodology would need to be versatile. Unlike electricity grids, DH systems are local by nature, as there are physical limitations to how far hot water may be transported and still retain its usefulness. Therefore, DH systems are individual entities. Different regions and communities have different preconditions and requirements with regard to heating. This fact entails that DH systems are not easily comparable. Thus, a highly standardised methodology to assess GHG emissions might not be the best option for DH systems. Instead, a methodology that also reflects the uniqueness of DH systems would be preferable.

As Figure 3 shows, allocating all GHG emissions from CHP production to electricity suggests GHG emission reductions in the studied system. Allocating all GHG emissions to heat instead suggests that several other heating options would be better. Figure 4 suggests that if GHG emissions are allocated to electricity, CHP production is preferable to industrial excess heat, with regard to GHG emissions. If GHG emissions are instead allocated to heat, Figure 4 suggests that industrial excess heat is better than all other heating options. These results point out two important things: that GHG emission calculations can basically suggest anything, depending on method and assumptions, and that in order for results to be comparable, production processes that result in the same product or by-product should be treated equally.

With regard to systems analyses of CHP production and industries with excess heat, we suggest that heat should be considered a by-product and thus not a carrier of GHG emissions. This not only facilitates the comparison of heat from different sources, but also emphasises the resource efficiency of utilising excess heat. When heat is considered a by-product, regardless of whether the main product is electricity or something else, the results from this paper suggest that GHG emissions are reduced in the studied system. In the case of CHP production, GHG emission reductions are attributable to the production of electricity, and in the case of industrial excess heat, GHG emission reductions are attributable to the use of heat that would otherwise be wasted.

When assessing a future DH system, previous research has recommended that a consequential perspective should be assumed. A consequential approach was used when analysing the exemplified technologies in section 4.1, and several different marginal production alternatives were considered. We suggest that when determining which are the marginal electricity and heat production technologies that should be used in an energy systems analysis, the local perspective should be kept in mind with regard to heat, while a European perspective should be assumed with regard to electricity. Although DH is a local 
product, electricity is not. What technologies are on the margin could thus differ between assessments, depending on their context.

This paper has analysed and discussed assessments of climate impact of DH systems. While GHG emissions are an important aspect of environmental impact, several other aspects have not been addressed. A methodology that reflects local conditions should also take environmental issues such as air pollution and waste management into consideration. For instance, landfilling could be reduced through waste incineration in a CHP or heat plant, and emissions of particulate matter from household boilers could be reduced through a switch to centralised heat production. Furthermore, the environmental impact of the DH system, and connected actors, could be quantified in an LCA. Further research could address all these aspects jointly and thereby construct a complete methodology for assessing the environmental impact of DH systems.

\section{Concluding remarks}

The aim of this paper has been to illuminate how methodology may affect results and to suggest how awareness of this may be used to identify GHG emission reduction possibilities in DH systems. The examples that are used to illustrate consequences of different methods, assumptions and system boundaries show that results differ greatly depending on methodological choices. Some conclusions may be drawn with regard to how methodology could be handled in order to identify GHG emission reduction opportunities:

- When assessing the climate impact of a DH system, local preconditions should be considered. With knowledge of what heat resources exist in the area and what the heating requirements are, resource efficiency can be evaluated and used as an input to GHG emission calculations.

- When assessing the climate impact of CHP production, GHG emissions should be allocated to the electricity. When assessing the climate impact of industrial excess heat, GHG emissions should be allocated to the industry's main product(s). Thus, heat should be considered a by-product regardless of its origin and as a result, CHPproduced heat and industrial excess heat would be assessed on equal terms.

In further research, the insights from this paper could be used in the development of a comprehensive methodology to assess the total environmental impact of DH systems. Such a methodology should encompass further aspects of environmental sustainability, such as air quality and waste management. We believe that a common methodology illuminating the environmental benefits of DH could contribute to greater use of Europe's heat potential in DH systems.

\section{Acknowledgements}

This paper was written under the auspices of the Energy Systems Programme, which is financed by the Swedish Energy Agency. Dr Sandra Backlund, Swedish Environmental Protection Agency, is gratefully acknowledged for valuable input to an early version of the paper. We would also like to thank two anonymous reviewers for helpful comments. 


\section{References}

Åberg, M., Henning, D., 2011. Optimisation of a district heating system with reduced heat demand due to energy efficiency measures in residential buildings. Energ. Policy 39, 78397852 .

Åberg, M., Widén, J., Henning, D., 2012. Sensitivity of district heating system operation to heat demand reductions and electricity price variations: A Swedish example. Energy 41, 525540 .

Beretta, G.P., Iora, P., Ghoniem, A.F., 2012. Novel approach for fair allocation of primary energy consumption among cogenerated energy-intensive products based on the actual local area production scenario. Energy 44, 1107-1120.

Borrion, A.L., McManus, M.C., Hammond, G.P., 2012. Environmental life cycle assessment of lignocellulosic conversion to ethanol: A review. Ren. Sust. Energ. Rev. 16, 4638-4650.

Brings Jacobsen, N., 2007. Do social factors really matter when companies engage in industrial symbiosis? Prog. Ind. Ecol. 4, 440-462.

Broberg Viklund, S., Johansson, M.T., 2014. Technologies for utilization of industrial excess heat: Potentials for energy recovery and $\mathrm{CO}_{2}$ emission reduction. Energ. Convers. Manage. 77, 369-379.

Burström von Malmborg, F., Forsberg, A., 2003. Choice of energy data in environmental assessment of the built environment. J. Environ. Assess. Pol. Manage. 5, 83-97.

Carlson, A., 2003. Energy systems and the climate dilemma - Reflecting the impact on $\mathrm{CO}_{2}$ emissions by reconstructing regional energy systems. Energ. Policy 31, 951-959.

Caserini, S., Livio, S., Giugliano, M., Grosso, M., Rigamonti, L., 2010. LCA of domestic and centralized biomass combustion: The case of Lombardy (Italy). Biomass Bioenerg. 34, 474482 .

Chertow, M.R., 2000. Industrial symbiosis: Literature and taxonomy. Annu. Rev. Energ. Env. 25, 313-337.

Connolly, D., Lund, H., Mathiesen, B.V., Werner, S., Möller, B., Persson, U., Boermans, T., Trier, D., Östergaard, P.A., Nielsen, S., 2014. Heat Roadmap Europe: Combining district heating with heat savings to decarbonise the EU energy system. Energ. Policy 65, 475-489.

Covenant of Mayors, 2012. Technical annex to the SEAP template instructions document: The emission factors. Available at http://www.eumayors.eu/IMG/pdf/technical_annex_en.pdf, 2012-08-20.

CPPD (Chalmers Power Plant Database), 2014. Version March 2014.

Difs, K., Danestig, M., Trygg, L., 2009. Increased use of district heating in industrial processes - Impacts on heat load duration. Appl. Energ. 86, 2327-2334. 
Djuric Ilic, D., Dotzauer, E., Trygg, L., Broman, G., 2014. Introduction of large-scale biofuel production in a district heating system - an opportunity for reduction of global greenhouse gas emissions. J. Clean. Prod. 64, 552-561.

Dotzauer, E., 2010. Greenhouse gas emissions from power generation and consumption in a Nordic perspective. Energ. Policy 38, 701-704.

EC (European Commission), 2009. Directive 2009/28/EC of the European Parliament and of the Council of 23 April 2009 on the use of energy from renewable sources and amending and subsequently repealing Directives 2001/77/EC and 2003/30/EC.

EC (European Commission), 2011. Commission implementing decision of 19 December 2011 establishing harmonised efficiency reference values for separate production of electricity and heat in application of Directive 2004/8/EC of the European Parliament and of the Council and repealing Commission Decision 2007/74/EC.

EC (European Commission), 2012. Directive 2012/27/EU of the European Parliament and of the Council of 25 October 2012 on energy efficiency, amending Directives 2009/125/EC and 2010/30/EU and repealing Directives 2004/8/EC and 2006/32/EC.

EC (European Commission), 2014. The urban dimension of EU policies - Key features of an EU urban agenda. COM(2014) 490 final.

Ekvall, T., Tillman, A.-M., Molander, S., 2005. Normative ethics and methodology for life cycle assessment. J. Clean. Prod. 13, 1225-1234.

GE (Göteborg Energi), 2014. Rya combined heat and power plant. [Rya kraftvärmeverk.] Available at http://www.goteborgenergi.se/om_oss/var_verksamhet/produktionsanlaggningar/rya_kraftvar meverk, 2014-06-27. In Swedish.

Gode, J., Martinsson, F., Hagberg, L., Öman, A., Höglund, J., Palm, D., 2011. Environmental fact book 2011. [Miljöfaktaboken 2011-Uppskattade emissionsfaktorer för bränslen, el, värme och transporter. Värmeforsk rapport 1183.] In Swedish.

Grönkvist, S., Sandberg, P., 2006. Driving forces and obstacles with regard to co-operation between municipal energy companies and process industries in Sweden. Energ. Policy 34, 1508-1519.

Grönkvist, S., Sjödin, J., Westermark, M., 2003. Models for assessing net $\mathrm{CO}_{2}$ emissions applied on district heating technologies. Int. J. Energ. Res. 27, 601-613.

Henning, D., Trygg, L., 2008. Reduction of electricity use in Swedish industry and its impact on national power supply and European $\mathrm{CO}_{2}$ emissions. Energ. Policy 36, 2330-2350.

Holmgren, K., 2006. Role of a district-heating network as a user of waste-heat supply from various sources - the case of Göteborg. Appl. Energ. 83, 1351-1367. 
Holmgren, K., Gebremedhin, A., 2004. Modelling a district heating system: Introduction of waste incineration, policy instruments and co-operation with an industry. Energ. Policy 32, 1807-1817.

Ingelstam, L., 2012. Systems - to think about society and technology. [System - att tänka över samhälle och teknik.] Energimyndigheten, Eskilstuna, Sweden. In Swedish.

Joelsson, A., Gustavsson, L., 2010. Energy efficiency measures and conversion of fossil fuel boiler systems in a detached house. Energ. Effic. 3, 223-236.

Johansson, D., Rootzén, J., Berntsson, T., Johnsson, F., 2012. Assessment of strategies for $\mathrm{CO}_{2}$ abatement in the European petroleum refining industry. Energy 42, 375-386.

Johansson, M.T., Söderström, M., 2011. Options for the Swedish steel industry - Energy efficiency measures and fuel conversion. Energy 36, 191-198.

Jönsson, J., Algehed, J., 2010. Pathways to a sustainable European kraft pulp industry: Tradeoffs between economy and $\mathrm{CO}_{2}$ emissions for different technologies and system solutions. Appl. Therm. Eng. 30, 2315-2325.

Jungmeier, G., Resch, G., Spitzer, J., 1998. Environmental burdens over the entire life cycle of a biomass CHP plant. Biomass Bioenerg. 15, 311-323.

Knutsson, D., Werner, S., Ahlgren, E.O., 2006. Combined heat and power in the Swedish district eating sector - impacts of green certificates and $\mathrm{CO}_{2}$ trading on new investments. Energ. Policy, 34, 3942-3952.

Lund, H., Werner, S., Wiltshire, R., Svendsen, S., Thorsen, J.E., Hvelplund, F., Mathiesen, B.V., 2014. 4th Generation District Heating (4GDH). Integrating smart thermal grids into future sustainable energy systems. Energy 68, 1-11.

Magnusson, D., 2012. Swedish district heating - A system in stagnation: Current and future trends in the district heating sector. Energ. Policy 48, 449-459.

Martin, M., 2013. Industrial symbiosis in the biofuel industry: Quantification of the environmental performance and identification of synergies. Dissertation No. 1507, Linköping University.

Martin, M., Eklund, M., 2011. Improving the environmental performance of biofuels with industrial symbiosis. Biomass Bioenerg. 35, 1747-1755.

Martin, M., Svensson, N., Eklund, M., 2013. Who gets the benefits? An approach for assessing the environmental performance of industrial symbiosis. J. Clean. Prod., In press.

Martin, M., Svensson, N., Fonseca, J., Eklund, M., 2014. Quantifying the environmental performance of integrated bioethanol and biogas production. Renew. Energy 61, 109-116.

Münster, M., Morthorst, P.E., Larsen, H.V., Bregnbaek, L., Werling, J., Lindboe, H.H., Ravn, H., 2012. The role of district heating in the future Danish energy system. Energy 48, 47-55. 
Nijkamp, P., Kourtit, K., 2013. The "New Urban Europe": Global Challenges and Local Responses in the Urban Century. Eur. Plan. Stud. 21, 291-315.

Odenberger, M., Unger, T., Johnsson, F., 2009. Pathways for the North European electricity supply. Energ. Policy 37, 1660-1677.

O’Rourke, D., Connelly, L., Koshland, C.P., 1996. Industrial ecology: a critical review. Int. J. Environ. Pollut. 6, 89-112.

Persson, U., Werner, S., 2011. Heat distribution and the future competitiveness of district heating. Appl. Energ. 88, 568-576.

Persson, U., Werner, S., 2012. District heating in sequential energy supply. Appl. Energ. 95, 123-131.

Rezaie, B., Rosen, M.A., 2012. District heating and cooling: Review of technology and potential enhancements. Energy 93, 2-10.

Rosen, M.A., 2008. Allocating carbon dioxide emissions from cogeneration systems: descriptions of selected output-based methods. J. Clean. Prod. 16, 171-177.

Schreiber, A., Zapp, P., Markewitz, P., Vögele, S., 2010. Environmental analysis of a German strategy for carbon capture and storage of coal power plants. Energ. Policy 38, 78737883.

SEA (Swedish Energy Agency), 2008. Analysis of methods to increase incentives for waste heat collaborations. [Analys av metoder för att öka incitament för spillvärmesamarbeten. ER 2008:16.] In Swedish.

Sjödin, J., Grönkvist, S., 2004. Emissions accounting for use and supply of electricity in the Nordic market. Energ. Policy 32, 1555-1564.

Sokka, L., Lehtoranta, S., Nissinen, A., Melanen, M., 2011. Analyzing the environmental benefits of industrial symbiosis. Life cycle assessment applied to a Finnish forest industry complex. J. Ind. Ecol. 15, 137-155.

SSNC (Swedish Society for Nature Conservation), 2013. Eco-labelling: Heat energy criteria. [Bra miljöval: Värmeenergi kriterier. 2013:1.] In Swedish.

Svensson, I-L., 2011. Evaluating system consequences of energy co-operation between industries and utilities. Dissertation No. 1407, Linköping University.

Svensson, I-L., Moshfegh, B., 2011. System analysis in a European perspective of new industrial cooling supply in a CHP system. Appl. Energ. 88, 5164-5172.

Thollander, P., Svensson, I-L., Trygg, L., 2010. Analyzing variables for district heating collaborations between energy utilities and industries. Energy 35, 3649-3656. 
Uppenberg, S., Brandel, M., Lindfors, L.-G., Marcus, H.-O., Stripple, H., Wachtmeister, A., Zetterberg, L., 2001. Environmental fact book for fuels. [Miljöfaktabok för bränslen Del 1. Huvudrapport. IVL Rapport B-1334B-2.] In Swedish.

Wetterlund, E., Pettersson, K., Magnusson, M., 2010. Implications of system expansion for the assessment of well-to-wheel $\mathrm{CO}_{2}$ emissions from biomass-based transportation. Int. J. Energ. Res. 34, 1136-1154.

Wolf, A., Eklund, M., Söderström, M., 2005. Towards cooperation in industrial symbiosis: considering the importance of the human dimension. Prog. Ind. Ecol. Int. J. 2, 185-199.

Wolf, A., Eklund, M., Söderström, M., 2007. Developing integration in a local industrial ecosystem - an explorative approach. Bus. Strateg. Environ. 16, 442-455.

WRI (World Resources Institute), 2007. Guidelines for quantifying GHG reductions from grid-connected electricity projects. 